This document is the accepted manuscript of the following publication:

IJLM. Accepted on November 06, 2019. Ref.: Ms. No. IJLM-D-19-00476R1.

Copyright lies with the publisher.

\title{
Comparing third molar root development staging in panoramic radiographs, extracted teeth and in cone beam computed tomography
}

(Running title: Third molar staging for age estimation)

\author{
Ademir Franco ${ }^{1,4}$, Flávia Vetter ${ }^{2}$, Eliane de Fátima Coimbra ${ }^{3}$, Ângela Fernandes ${ }^{2}$, \\ Patrick Thevissen $^{1}$
}

1. Department of Imaging and Pathology, Forensic Odontology, KU Leuven, Kapucijnenvoer 7, block B, 3000, Leuven, Belgium.

2. Department of Stomatology, Federal University of Paraná, Av. Lothário Meissner 632, Postal code: 80.210-170, Jardim Botânico, Curitiba, Paraná, Brazil.

3. Post-graduation program in Information Science, Management and Technology, Federal University of Paraná, Av. Lothário Meissner 632, Postal code: 80.210-170, Jardim Botânico, Curitiba, Paraná, Brazil.

4. Dvision of Oral Radiology, Faculdade São Leopoldo Mandic, Instituto de Pesquisas São Leopoldo Mandic, R. Dr. José Rocha Junqueira 13, Postal code:13.045-755, Ponte Preta, Campinas, São Paulo, Brazil.

Corresponding author:

Ademir Franco, $\mathrm{PhD}$

E-mail: franco.gat@gmail.com

ORCID: Ademir Franco (0000-0002-1417-2781); Patrick Thevissen (0000-0003-0890-6264) 


\section{Abstract}

This study aimed at performing and comparing third molar development staging in extracted teeth $(\mathrm{EX})$, in panoramic radiographs (PAN) and in cone beam computed tomography (CBCT). Extracted third molars $(\mathrm{n}=158,95$ maxillary, 63 mandibular) from 102 patients (36 males, 66 females) having at least one preoperative PAN and one CBCT volume were studied. Third molar development staging was performed in PAN, EX and in CBCT using Gleiser et al. (1955) technique modified by Köhler et al (1994). A polytomous logistic regression model was used to compare the staging performed EX and in CBCT with the gold standard staging in PAN. In all the pair-wise comparisons between staging modalities 100 third molars $(63.3 \%)$ were equally staged. The other 58 third molars $(36.7 \%)$ were staged with a maximum difference of one stage. No statistically significant differences between the three staging modalities were detected $(\mathrm{p}=0.26)$. The comparison between EX and PAN staging revealed higher similarity $(\mathrm{p}=0.98$ in stages $5-10)$ than the comparison between CBCT and PAN staging $(\mathrm{p}=0.81$ in stages 5, 7 and 9, and 0.80 in stages 6,8 and 10). The studied third molar staging technique originally designed in PAN can be applied for third molar staging EX and in CBCT.

Keywords: cone beam computed tomography; forensic dentistry; panoramic radiography; third molar

\section{Introduction}

Dental age estimation is performed in forensic dentistry both in the living and the deceased [1]. In the living, the methods are non-destructive and the used medical 
imaging is applied with minimal radiation doses [2, 3]. Panoramic radiographs (PAN) offer the perfect balance between the number of visible dental and maxillofacial structures and the required radiation dose. Age estimation investigations are most commonly requested for asylum seekers [4], adopted children [5], sports players [6] and juvenile offenders [7]. To retrieve more detailed information from the human teeth, in the deceased, additional exams such as computed tomography [8-10] may be added to conventional bidimensional radiography. Dental age estimation of the deceased is integrated in most human identification protocols $[11,12]$.

Developing third molars are assessed as source of age-related information in subadults together with the maturation of all other teeth earlier in their development [13, 14]. Most techniques used for dental development registration classify tooth development in pre-defined stages observed in PAN [15-17]. In the Köhler et al. [16] technique, the crown, root and apex development of maxillary and mandibular third molars are classified in three, five and two developmental stages, respectively. Over the last decades, this technique was widely used in population-specific age estimation studies [18-21].

All human dental development staging techniques were originally designed on conventional radiographs. Hence, a radiograph inherent dental morphology is registered and used for stage allocation. Analyses of extracted teeth (EX) and in computed tomography - especially cone beam computed tomography (CBCT) - enable a tridimensional visualization of the dental morphology. Staging techniques originally designed on radiographs should be tested for reproducibility in EX and in CBCT. This study aimed to compare tooth development staging in PAN with EX, and in CBCT.

Material and methods 
This observational study was performed with ethical clearance from the institutional Committee of Ethics in Human Research (protocol: \#1.363.822).

Prospectively between 2015 and 2018, 102 patients (36 males and 66 females), from South Brazil, aged between 16 and 50 years old (Table 1) were selected based on the diagnosis of at least one third molar to be extracted. From each selected subject the latest 3 months before surgery a PAN and a CBCT scan were taken for diagnosis and surgical planning. The extracted third molars had no decay and were not conservatively restored. Third molars fractured during extraction or registered with medical images of poor quality were excluded. After surgery, all the third molars were cleaned with distilled water by the staff of the institutional tooth databank and were kept in formalin. One hundred fifty-eight third molars were sampled (95 maxillary and 63 mandibular). The PAN were acquired with an Orthopantomograph OP200D unit (Instrumentarium Dental, Tuusula, Finland) set with $66 \mathrm{Kv}$, automatically corrected mAs between each acquisition, and acquisition time of 14.1 seconds. The CBCT was taken with an iCAT Next Generation unit (Imaging Sciences International, Hatfield, PA, USA) set with field of view of $16 \mathrm{x} 13 \mathrm{~cm}, 0.25$ voxel, $37.07 \mathrm{mAs}, 120 \mathrm{kVp}$, and acquisition time of 26.7 seconds.

In all the selected subjects third molar crown developed was complete. Each third molar root was staged in PAN, EX and in CBCT, according Köhler et al. [16] (Fig. 1). The PAN staging (gold standard staging) was accomplished by two examiners separately: both forensic odontologists with 3 (main examiner) and 8 years of experience, respectively. In case of disagreement a consensus stage was allocated in agreement with a third examiner: a maxillofacial radiologist with 25 years of experience. PAN were analyzed using Windows 10 image viewer (Microsoft, Redmond, WA, USA) in a 15.6" touch screen ThinkPad E580 notebook (Lenovo Group Ltd., 
Morrisville, NC, USA). The EX analysis was performed using a black background and a 60mm magnifier lens (magnification up to 200\%). The CBCT analysis was established using tools for multiplanar view and 3D reconstructions in a workstation with iCAT Vision (Imaging Sciences International, Hatfield, PA, USA) and a Dell 22" LED LCD (1080p) screen (Dell Inc., Round Rock, TX, USA). Third molar roots were analyzed in each CBCT image series scrolling all the slices, as well as navigating the 3D reconstructions. The most advanced third molar developmental stage observed in axial, coronal or sagittal plane was considered. Third molars without developed root furcation or with fused roots received the same developmental stage for each root position and roots that could not be visualized or distinguished were not staged. Agreement was established when stage allocation in EX or CBCT matched the stage allocation performed in PAN.

Weighted Kappa statistics was used to quantify the intra- and inter-examiner agreement on repeated PAN, EX and CBCT staging of 40 randomly selected third molars. The interval between the analyses was 14 days. The obtained data was analyzed with descriptive statistics. Pair-wise third molar development staging comparisons between PAN and EX or CBCT were established and tested with Chi square tests. A polytomous logistic regression model with third molar stage as explanatory variable (y axis) and the type of staging modality as response variable ( $\mathrm{x}$ axis) was developed to compare the stage allocation between the staging modalities. The statistical analyses were performed with SPSS v21 (IBM Corp. Armonk, NY, USA) and R (The R Foundation, Vienna, Austria), the significance levels was set with $\mathrm{p}<0.05$ and the confidence interval at $95 \%$.

Results 
Weighted Kappa statistics showed excellent intra-examiner agreement in third molar staging in PAN (0.91), EX (0.93) and CBCT (0.91). The inter-examiner agreement in third molar staging was excellent in PAN (0.8) and EX (0.86), and good (0.69) in CBCT [22].

The third molars consisted of 46 maxillary right (Federation Dentaire Internationale - FDI: 18), 49 maxillary left (FDI: 28), 32 mandibular left (FDI: 38) and 31 mandibular right (FDI: 48). Sixty-two third molars had fused roots (FDI $18 \mathrm{n}=24$; FDI 28 n=23; FDI 48 n=9; FDI 38 n=6).

The roots of one-hundred third molars $(63.3 \%)$ were equal staged in each staging modality (PAN, EX and CBCT). The remaining third molar roots $(36.7 \%)$ were staged with a maximum difference of one stage compared to the PAN staging. In figures 2, 3 and 4 the obtained stages were distributed based on age and plotted per staging modality (PAN, EX and CBCT) for mesial/mesio-buccal, distal/disto-buccal and palatal third molar roots, respectively. A detailed description of the frequency of stages per root in PAN, EX and CBCT is reported in table 2.

The Chi-square test revealed no statistically significant differences for the pairwise comparison between PAN and EX $(\mathrm{p}=0.26)$ and between PAN and CBCT $(\mathrm{p}=0.26)$. The polytomous logistic regression model showed high similarity in stage allocation between PAN and EX, per stage all differences in stage allocation reached $\mathrm{p}=0.98$. Between PAN and CBCT, the difference in stage allocation reached $\mathrm{p}=0.81$ for stages 5,7 and 9 and $\mathrm{p}=0.80$ for stages 6,8 and 10 (Table 3 ).

Discussion

Staging the crown and root formation of developing teeth is one of the most used techniques to register the tooth developmental status in forensic scientific and practice [23-25]. Currently, most dental staging techniques were developed from bidimensional 
representations of the human teeth in PAN. In practice, dental age estimation requires the application of methods as they were originally designed. This implicates that the used staging technique should be applied on the staging modality it was developed on. If not, it may lead to mistakes reflected in the age estimates. The current study compared the staging technique of Köhler et al. [16], established in PAN, in third molars assessed EX and in CBCT. The assessment EX was justified because in practice it might be performed in skeletal remains, as well as it may represent a contribution to human identifications performed in medico-legal facilities not equipped with imaging devices. CBCT, on the other hand, was justified because in practice it enables the analysis of jaws collected from skeletal remains or even body parts collected from mutilated victims of violent death. It is also important to highlight that some CBCT devices are designed to scan patients lying in a supine position, which could be an alternative to assess dental morphology and development in intact cadavers.

In this study, the analysis EX was performed after the surgery and within 90 days from the medical image acquisitions. It is important to note that the patients were sampled by convenience to include in this study the largest number of third molar stages as possible. However, third molar extraction is not common in children and young adolescents. For this reason, no crown formation stages and few early root formation stages were sampled.). On the other hand third molar extraction is mainly performed for prophylactic reasons [26] in the age range between 20 and 39 years old [27]. In this age range, third molars are expected to be in late or complete stage of root formation [25]. Accordingly, the mean age of the patients sampled in this study was 24.01 years $( \pm 4.88)$.

Köhler et al. [16] staging was the technique of choice in the present study because it is a consolidated approach previously applied for third molar age estimation 
in several studies with different populations worldwide [2, 14, 18-21]. In practice, Köhler et al. [16] staging technique is officially used in institutional protocols for age estimation of the living, such as the "Triple Test for Unaccompanied Fugitives", developed in Belgium [28]. Moreover, the population sampled in this study was originally from South Brazil - a region with strong European ancestral influence compatible with Köhler's original German sample [19]. Finally, there was history of the research team with third molar dental age estimation studies with Köhler et al. [16] staging, denoting familiarization of the examiners with the technique $[2,19]$.

Third molars in Köhler et al. [16] stage 8 (complete root formation), 9 (1/2 of apex formation) and 10 (complete apex formation) are the most difficult to distinguish [29]. Related highest disagreements between observers were reported [30]. Figures 2-4 illustrate the agreement between staging in PAN, EX, and in CBCT. For root complete (stage 8) and apex complete (stage 10), proper staging agreement was detected between the different staging modalities in all third molar roots. Differently, apex $1 / 2$ (stage 9) presented discrepant outcomes. This finding may be explained by the bidimensional image projection and superimposition of adjacent maxillofacial structures that occur in PAN and hamper the visualization of partial apex formation. However, it is important to note that despite the clearer visualization of teeth feasible in EX and CBCT, lower observer agreement values may occur because the examiners are more used to stage dental development in PAN - as proposed by Köhler et al. [16]. In practice, discrepancies in staging third molars according to Köhler et al. [16], in different image modalities, especially in stage apex $1 / 2$, must be taken into account as it could influence age estimates. On the other hand, it has to be noted that stage 9 covers the shortest maturation period of all Köhler et al. [16] stages. Consequently allocating an adjacent 
stage will have the least impact on age predictions compared to adjacent misallocating other Köhler et al. [16] stages.

Considering third molar stages as outcome variable and the type of image modality as dependent variable, the polytomous logistic regression model compared the staging performance between PAN and EX, and PAN and CBCT. The comparison was separately accomplished for each of the third molar stages from 5 to 10 . Between PAN and EX, a minimal difference was observed in staging performances for each studied third molar stage $(\mathrm{p}=0.98)$. Between PAN and CBCT the differences were slightly higher $(\mathrm{p}=0.81$ in stages 5,7 and 9 , and $\mathrm{p}=0.80$ in stages 6,8 and 10 ), but still not statistically significant $(\mathrm{p}>0.05)$. The discrete discrepancy that makes the comparison between PAN and EX less different than PAN and CBCT relies on differences in stage allocation performed EX or on CBCT. Stage allocation EX is more straight-forward than on $\mathrm{CBCT}$. It requires observer experience to combine during $\mathrm{CBCT}$ evaluations a detailed slice-by-slice multiplanar navigation through the dental structure with an assessment of the obtained 3D reconstruction [31]. Additionally, the surrounding tissues and the internal tooth information present on CBCT can be disturbing factors influencing the image quality and consequently the stage allocation. Further on the inherent loss of image information between slices may complicate the detection of the exact threshold between Köhler et al. [16] stages, especially in late root formation.

Despite the broad use of panoramic radiographs for dental age estimation (especially because of destructive procedures are not applicable to the living), histological sections [32, 33] remain the pathway for a deeper look at dental development. In this study, destructive procedures in the collected sample were not feasible, but future studies are encouraged to test third molar staging in from a microscopic point of view. Other existing methods for dental age estimation in extracted 
teeth also could be investigated, especially in third molars with complete root formation (adults), such as those based on root translucency [34] and size of the pulp chamber [35]. Additionally, larger samples should be addressed to cover all third molar developmental stages (including crown stages). Moreover, staging on other medical imaging techniques such as peri-apical radiographs should be compared with the current gold standard (PAN).

Conclusion

The third molar staging technique originally proposed by Köhler et al. [16] in PAN can be applied with similar performance in third molars analyzed EX and in CBCT. However, care has to be taken in stages of late root formation, especially in stage apex $1 / 2$ closed (stage 9), due to minor discrepancies in stage allocation between PAN and CBCT.

Acknowledgements

The authors would like to express their gratitude to the academic staff.

Compliance with ethical statement

Funding: none; conflict of interest: none; ethical approval: 1.363.822; informed consent: $\mathrm{n} / \mathrm{a}$ for radiographic collection (retrospective) and applied for third molar donation (prospective).

References 
1. Cericato GO, Franco A, Bittencourt MAV, Nunes MAP, Paranhos LR (2016) Correlating skeletal and dental developmental stages using radiographic parameters. J Forensic Legal Med 42:13-18.

2. Kumagai A, Willems G, Franco A, Thevissen P (2018) Age estimation combining radiographic information of two dental and four skeletal predictors in children and subadults. Int J Legal Med 132:1769-1777.

3. Thevissen PW, Kvaal SI, Willems G (2012) Ethics in age estimation of unaccompanied minors. J Forensic Odontostomatol 30:84-102.

4. Solheim T, Vonen A (2006) Dental age estimation, quality assurance and age estimation of asylum seekers in Norway. Forensic Sci Int 159:56-60.

5. Macha M (2017) Estimation of correlation between chronological age, skeletal age and dental age in children- a cross-sectional study. J Clin Diag Res 11:1-4.

6. Silva R, Rodrigues L, Felter M, Araújo M (2018) A interface entre a odontologia legal e a odontologia do esporte. Rev Bras Odont Legal 5:69-84.

7. Sykes L, Bhayat A, Bernitz H (2017) The effects of the refugee crisis on age estimation analysis over the past 10 years: a 16-country survey. Int J Envir Res Pub Health 14:630.

8. Asif MK, Nambiar P, Mani SA, Ibrahim NB, Khan IM, Sukumaran P (2018) Dental age estimation employing CBCT scans enhanced with Mimics software: Comparison of two different approaches using pulp/tooth volumetric analysis. J Forensic Legal Med 54:53-61.

9. Pinchi V, Pradella F, Buti J, Baldinotti C, Focardi M, Norelli GA (2015) A new age estimation procedure based on the 3D CBCT study of the pulp cavity and hard tissues of the teeth for forensic purposes: A pilot study. J Forensic Legal Med 36:150-157. 
10. Franco A, Thevissen P, Coudyzer W, Develter W, Van de Voorde W, Oyen R et al. (2013) Feasibility and validation of virtual autopsy for dental identification using the Interpol dental codes. J Forensic Legal Med 20:248-254.

11. Adserias-Garriga J, Thomas C, Ubelaker DH, Zapico SC (2018) When forensic odontology met biochemistry: Multidisciplinary approach in forensic human identification. Arch Oral Biol 87:7-14.

12. Machado MA, Daruge Júnior E, Fernandes MM, Lima IFP, Cericato GO, Franco A et al. (2018) Effectiveness of three age estimation methods based on dental and skeletal development in a sample of young Brazilians. Arch Oral Biol 85:166-171.

13. Kedarisetty S, Rao G, Rayapudi N, Korlepara R (2015) Evaluation of skeletal and dental age using third molar calcification, condylar height and length of the mandibular body. J Forensic Dent Sci 7:121.

14. Thevissen PW, Galiti D, Willems G (2012) Human dental age estimation combining third molar(s) development and tooth morphological age predictors. Int J Legal Med $126: 883-887$.

15. Gleiser I, Hunt E (1955) The permanent mandibular first molar: its calcification, eruption and decay. Am J Phys Anthropol 13:253-283.

16. Köhler S, Schmelzle R, Loitz C, Puschel K (1994) Development of wisdom teeth as a criterion of age determination. Ann Anat 176:339-345.

17. Solari AC, Abramovitch K (2002) The accuracy and precision of third molar development as an indicator of chronological age in Hispanics. J Forensic Sci 47:531535.

18. Altalie S, Thevissen P, Fieuws S, Willems G (2014) Optimal Dental age estimation practice in United Arab Emirates' children. J Forensic Sci 59:383-385. 
19. Franco A, Thevissen P, Fieuws S, Souza PHC, Willems G (2013) Applicability of Willems model for dental age estimations in Brazilian children. Forensic Science International 231:401.e1-4

20. Yusof MYPM, Cauwels R, Martens L (2015) Stages in third molar development and eruption to estimate the 18-year threshold Malay juvenile. Arch Oral Biol 60:15711576.

21. Ramanan N, Thevissen P, Fleuws S, Willems G (2012) Dental age estimation in Japanese individuals combining permanent teeth and third molars. J Forensic Odontostomatol 30:34-39.

22. Svanholm H, Starklint H, Gundersen HJ, Fabricius J, Barlebo H, Olsen S (1989) Reproducibility of histomorphologic diagnoses with special reference to the kappa statistic. Acta Pathol Microbiol Immunol Scand 97:689-698.

23. Arge S, Boldsen JL, Wenzel A, Holmstrup P, Jensen ND, Lynnerup N (2018) Third molar development in a contemporary Danish 13-25 year old population. Forensic Sci Int 289:12-17.

24. Bagherpour A, Anbiaee N, Partovi P, Golestani S, Afzalinasab S (2012) Dental age assessment of young Iranian adults using third molars: A multivariate regression study. J Forensic Legal Med 19:407-412.

25. Gunst K, Mesotten K, Carbonez A, Willems G (2003) Third molar root development in relation to chronological age: A large sample sized retrospective study. Forensic Sci Int 136:52-57.

26. Cunha-Cruz J, Rothen M, Spiekerman C, Drangsholt M, McClellan L, Huang GJ (2014) Recommendations for Third Molar Removal: A Practice-Based Cohort Study. Am J Pub Health 104:735-743. 
27. Kautto A, Vehkalahti MM, Ventä I (2018) Age of patient at the extraction of the third molar. Int J Oral Maxillofac Surg 47:947-951.

28. Willems G, Thevissen P (2013) The Triple Test: age estimation protocol for unaccompanied fugitives developed at the KU Leuven, Belgium. J Forensic Odontostomatol 31:77-78.

29. Kullman L, Tronje G, Teivens A, Lundholm A (1996) Methods of reducing observer variation in age estimation from panoramic radiographs. Dentomaxillofac Radiol 25:173-178.

30. Thevissen PW, Khalaf B, Fieuws S, Willems G (2016) Validating tooth development staging techniques based on the prediction of the mature root lengths. Proceed Am Acad Forensic Sci 68:654.

31. Shukla S, Chug A, Afrashtehfar K (2017) Role of cone beam computed tomography in diagnosis and treatment planning in dentistry: An update. J Int Soc Prev Comm Dent $7: 125$.

32. Calonius PEB, Lunin M, Stout F (1970) Histologic criteria for age estimation of the developing human dentition. Oral Surg Oral Med Oral Pathol 29:869-876.

33. Ubelaker DH, Khosrowshahi H (2019) Estimation of age in forensic anthropology: historical perspective and recent methodological advances. Forensic Sci Res 4:1-9.

34. Solheim T (1989) Dental root translucency as an indicator of age. Scand J Dent Res 97:189-197.

35. De Angelis D, Gibelli D, Fabbri P, Cattaneo C (2015) Dental age estimation helps create a new identity. Am J Forensic Med Pathol 36:219-220. 


\section{Legends of figures}

Fig. 1 - Third molar staging performed according to Köhler et al. [16] in extracted teeth, panoramic radiographs and cone beam computed tomography (CBCT)

Legend: A: extracted third molars; B: third molars in panoramic radiographs; C: third molars in CBCT. Third molar staging was separately performed for each of the third molar's roots. Teeth with fused roots were classified with a single stage. In this study, stages $5,6,7,8,9$ and 10 (images from 1 to 6 , respectively) were the most detected in the sampled patients. According to Köhler et al. [16], these stages present root 1/4 complete (A1, B1 and $\mathrm{C} 1)$; root $1 / 2$ complete (A2, B2 and $\mathrm{C} 2)$; root $3 / 4$ complete (A3, B3 and $\mathrm{C} 3$ ); root complete (A4, B4 and C4); apex 1/2 complete (A5, B5 and C5); and apex complete (A, B and C6), respectively.

Fig. 2 - Mesial or mesio-buccal roots staging plotted per image modalities

Legend: Köhler et al. [16] stages from 4 to 10: root initial formation; root 1/4 complete; root $1 / 2$ complete; root $3 / 4$ complete; root complete; apex 1/2 complete; and apex complete, respectively. Circle: staging in panoramic radiograph; Square: staging in extracted teeth; Red Mark: staging in cone beam computed tomography. Teeth 18, 28, 38 and 48: maxillary right, maxillary left, mandibular left and mandibular right third molars according to the Federation Dentaire Internationale (FDI). Age expressed in years. Superimposition of the symbols indicates agreement in staging.

Fig. 3 - Distal or disto-buccal roots staging plotted per image modalities Legend: Köhler et al. [16] stages from 4 to 10: root initial formation; root $1 / 4$ complete; root $1 / 2$ complete; root $3 / 4$ complete; root complete; apex $1 / 2$ complete; and apex complete, respectively. Circle: staging in panoramic radiograph; Square: staging in extracted teeth; 
Red Mark: staging in cone beam computed tomography. Teeth 18, 28, 38 and 48: maxillary right, maxillary left, mandibular left and mandibular right third molars according to the Federation Dentaire Internationale (FDI). Age expressed in years. Superimposition of the symbols indicates agreement in staging.

Fig. 4 - Palatal roots staging plotted per image modalities

Legend: Köhler et al. [16] stages from 5 to 10: root $1 / 4$ complete; root $1 \frac{1}{2}$ complete; root $3 / 4$ complete; root complete; apex 1/2 complete; and apex complete, respectively. Circle: staging in panoramic radiograph; Square: staging in extracted teeth; Red Mark: staging in cone beam computed tomography. Teeth 18 and 28: maxillary right and maxillary left third molars according to the Federation Dentaire Internationale (FDI). Age expressed in years. Superimposition of the symbols indicates agreement in staging. 
Fig. 1

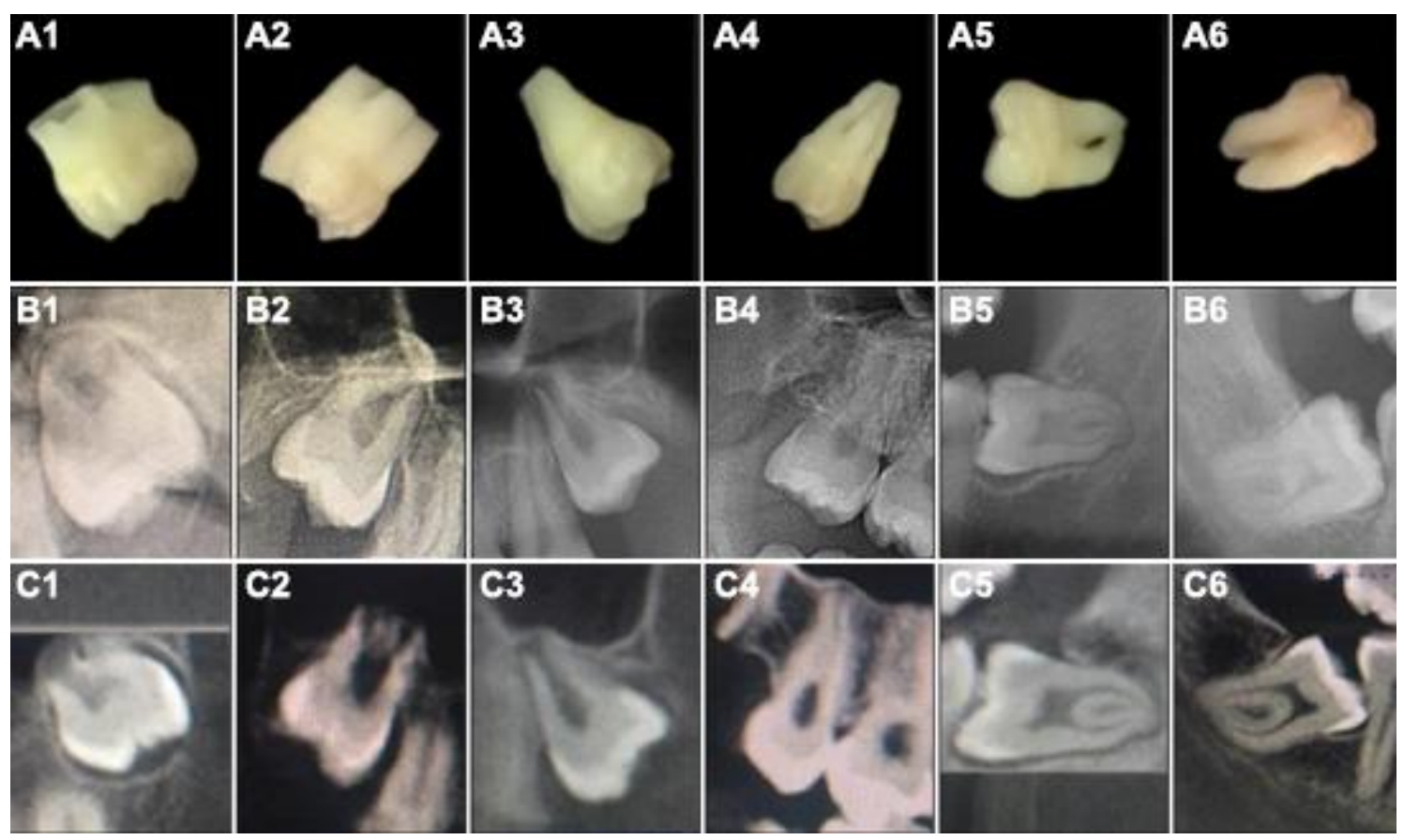

Fig. 2

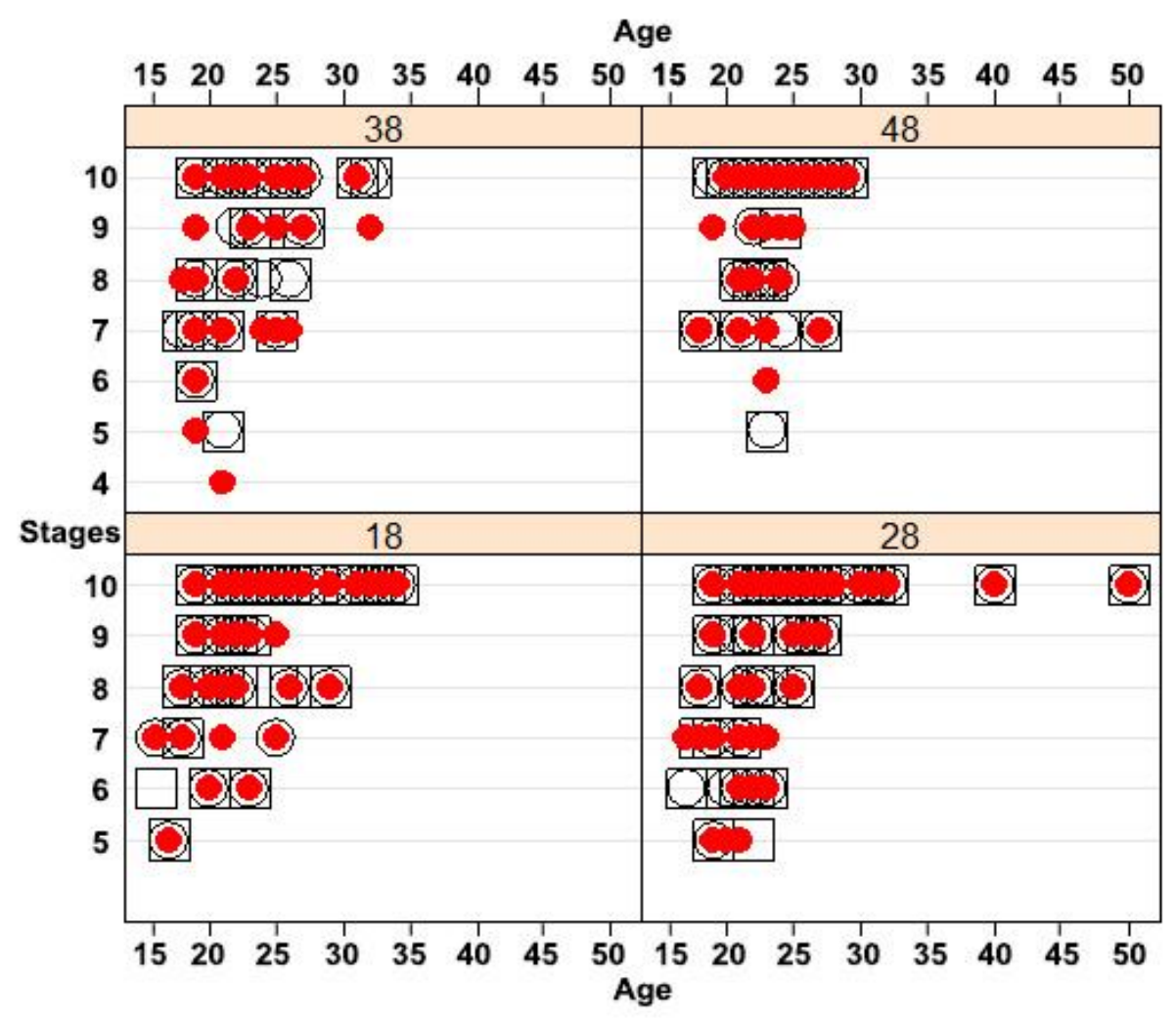


Fig. 3

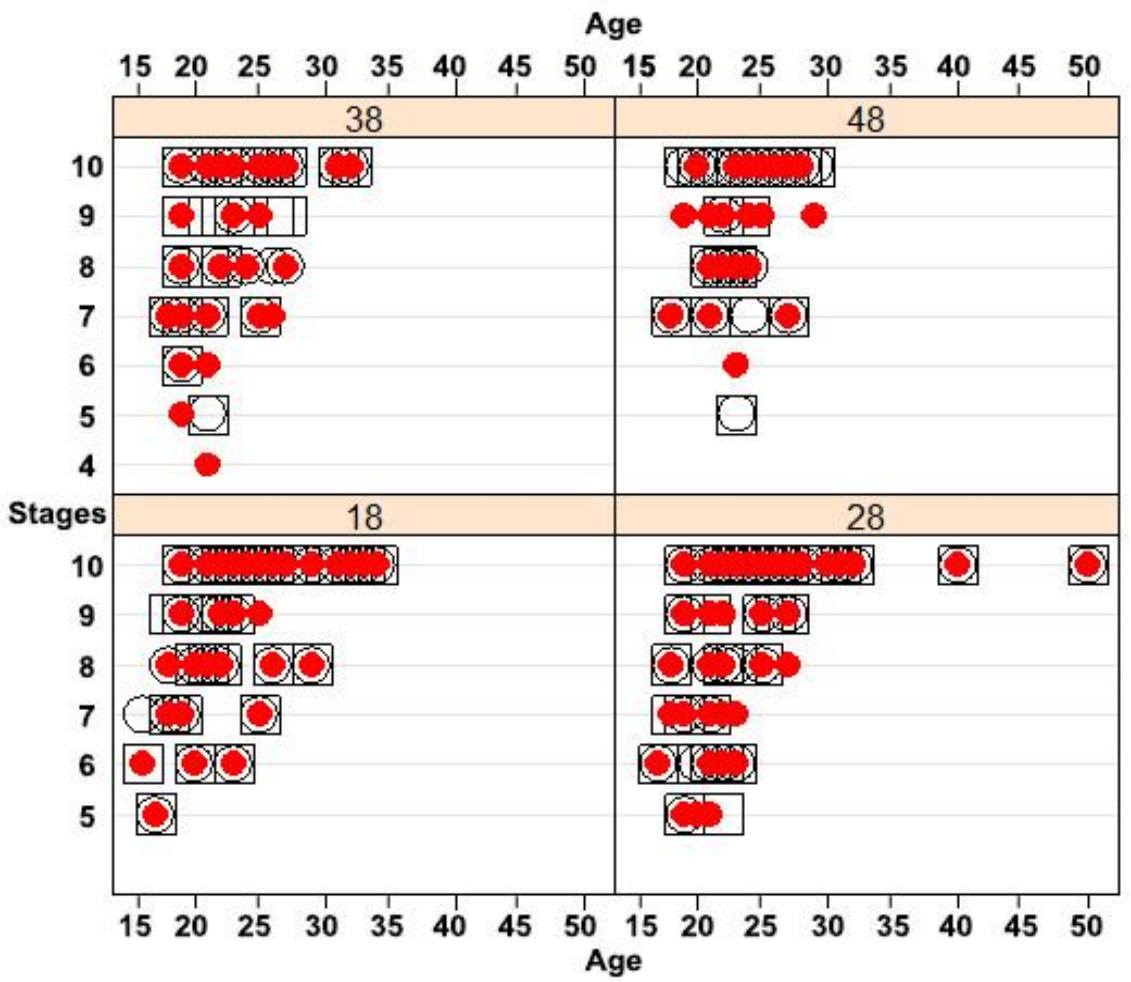

Fig.4

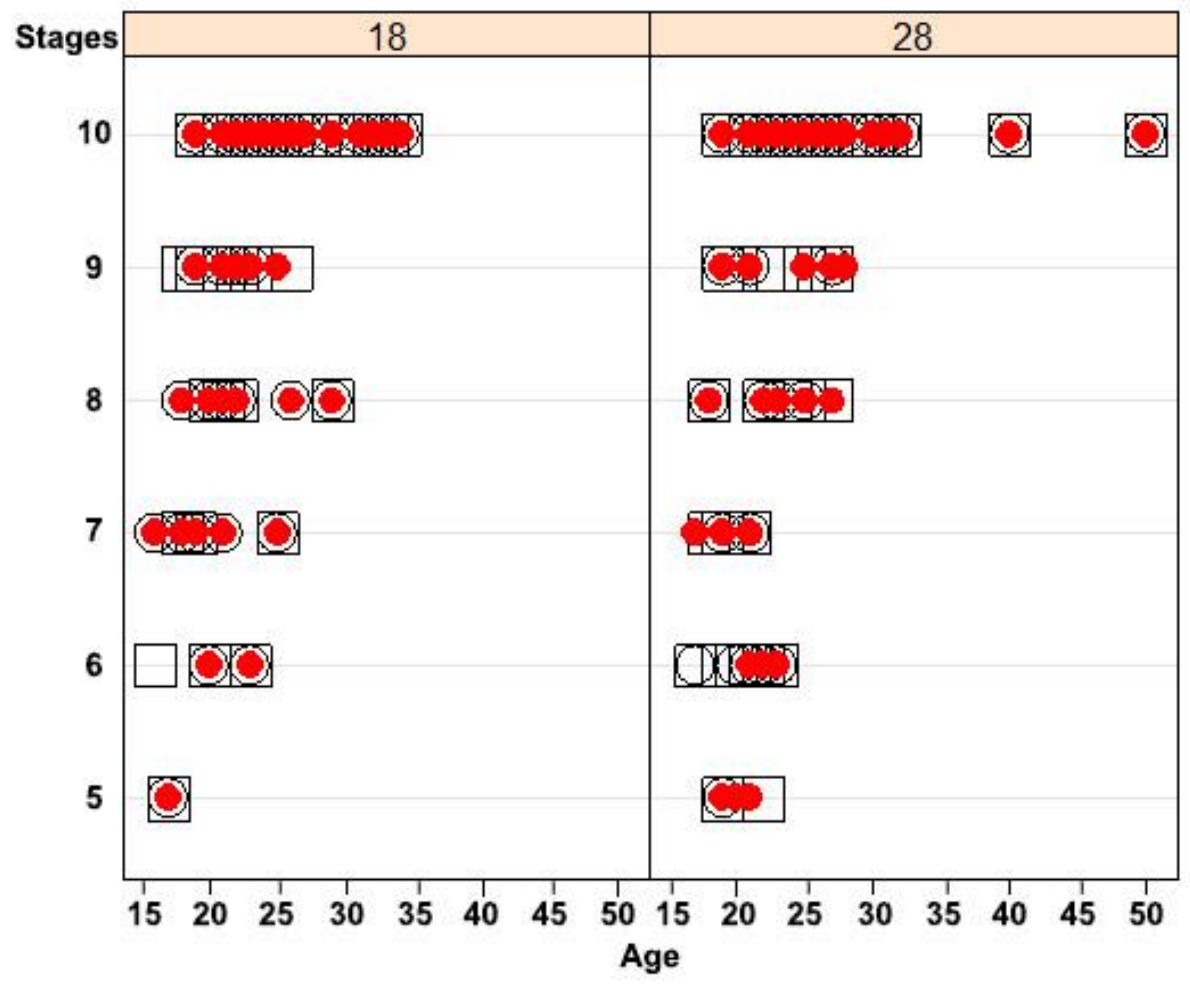


Table 1 - Absolute and relative distribution of the participants of this study based on sex and age

\begin{tabular}{|llll|}
\hline $\begin{array}{l}\text { Age } \\
\text { range }\end{array}$ & $\begin{array}{l}\text { Females } \\
\mathrm{n}(\%)\end{array}$ & $\begin{array}{l}\text { Males } \\
\mathrm{n}(\%)\end{array}$ & $\begin{array}{l}\text { Overall } \\
\mathrm{n}(\%)\end{array}$ \\
\hline $16-16.9$ & 0 & $1(2.8)$ & $1(1.0)$ \\
$17-17.9$ & $2(3.0)$ & 0 & $2(2.0)$ \\
$18-18.9$ & $2(3.0)$ & 0 & $2(2.0)$ \\
$19-19.9$ & $5(7.6)$ & $8(22.2)$ & $13(12.7)$ \\
$20-20.9$ & $2(3.0)$ & $1(2.8)$ & $3(2.9)$ \\
$21-21.9$ & $10(15.2)$ & $2(5.6)$ & $12(11.8)$ \\
$22-22.9$ & $8(12.1)$ & $1(2.8)$ & $9(8.8)$ \\
$23-23.9$ & $6(9.1)$ & $4(11.1)$ & $10(9.8)$ \\
$24-24.9$ & $4(6.1)$ & $4(11.1)$ & $8(7.8)$ \\
$25-25.9$ & $7(10.6)$ & $4(11.1)$ & $11(10.8)$ \\
$26-26.9$ & $5(7.6)$ & $4(11.1)$ & $9(8.8)$ \\
$27-27.9$ & $5(7.6)$ & $2(5.6)$ & $7(6.9)$ \\
$28-28.9$ & $2(3.0)$ & $1(2.8)$ & $3(2.9)$ \\
$29-29.9$ & $1(1.5)$ & $1(2.8)$ & $2(2.0)$ \\
$30-30.9$ & $1(1.5)$ & 0 & $1(1.0)$ \\
$31-31.9$ & 0 & $2(5.6)$ & $2(2.0)$ \\
$32-32.9$ & $3(4.5)$ & 0 & $3(2.9)$ \\
$33-33.9$ & $1(1.5)$ & 0 & $1(1.0)$ \\
$34-34.9$ & $1(1.5)$ & 0 & $1(1.0)$ \\
$40-40.9$ & 0 & $1(2.8)$ & $1(1.0)$ \\
$50-50.9$ & $1(1.5)$ & 0 & $1(1.0)$ \\
Total & $66(100.0)$ & $36(100.0)$ & $102(100.0)$ \\
\hline
\end{tabular}

$\mathrm{n}$ : absolute values; \%: relative values. 
Table 2 - Third molar stages based on the technique of Kohler et al. (1994) distributed separately per tooth (\#18, 28, 38 and 48), roots (mesio-buccal, disto-buccal and palatal) and type of analysis (extracted, in panoramic radiographs and in CBCT scans)

\begin{tabular}{|c|c|c|c|c|c|c|c|c|c|c|c|c|c|c|c|c|c|c|c|c|}
\hline \multirow{2}{*}{ Tooth } & \multicolumn{7}{|c|}{ Mesial or mesio-buccal root } & \multicolumn{7}{|c|}{ Distal or disto-buccal root } & \multicolumn{6}{|c|}{ Palatal root } \\
\hline & 4 & 5 & 6 & 7 & 8 & 9 & 10 & 4 & 5 & 6 & 7 & 8 & 9 & 10 & 5 & 6 & 7 & 8 & 9 & 10 \\
\hline$\# 18$ & 0 & 3 & 7 & 8 & 25 & 19 & 76 & 0 & 3 & 8 & 10 & 24 & 16 & 77 & 3 & 7 & 13 & 20 & 16 & 79 \\
\hline Extracted & 0 & 1 & 3 & 1 & 9 & 6 & 26 & 0 & 1 & 3 & 3 & 7 & 6 & 26 & 1 & 3 & 3 & 6 & 7 & 26 \\
\hline Panoramic & 0 & 1 & 2 & 3 & 9 & 7 & 25 & 0 & 1 & 2 & 4 & 8 & 5 & 27 & 1 & 2 & 5 & 7 & 4 & 28 \\
\hline $\mathrm{CBCT}$ & 0 & 1 & 2 & 4 & 7 & 6 & 25 & 0 & 1 & 3 & 3 & 9 & 5 & 24 & 1 & 2 & 5 & 7 & 5 & 25 \\
\hline \#28 & 0 & 6 & 18 & 17 & 15 & 21 & 70 & 0 & 6 & 19 & 17 & 16 & 16 & 74 & 6 & 20 & 12 & 15 & 16 & 77 \\
\hline Extracted & 0 & 2 & 7 & 5 & 4 & 8 & 23 & 0 & 2 & 7 & 5 & 4 & 7 & 24 & 2 & 8 & 4 & 3 & 6 & 26 \\
\hline Panoramic & 0 & 1 & 7 & 4 & 6 & 7 & 25 & 0 & 1 & 7 & 4 & 7 & 4 & 27 & 1 & 7 & 4 & 6 & 5 & 27 \\
\hline CBCT & 0 & 3 & 4 & 8 & 5 & 6 & 22 & 0 & 3 & 5 & 8 & 5 & 5 & 23 & 3 & 5 & 4 & 6 & 5 & 24 \\
\hline \#38 & 1 & 3 & 5 & 18 & 15 & 12 & 43 & 1 & 3 & 6 & 18 & 17 & 10 & 40 & & & & & & \\
\hline Extracted & 0 & 1 & 2 & 5 & 5 & 4 & 15 & 0 & 1 & 2 & 5 & 5 & 6 & 13 & & & & & & \\
\hline Panoramic & 0 & 1 & 2 & 6 & 5 & 4 & 15 & 0 & 1 & 2 & 6 & 7 & 2 & 15 & & & & & & \\
\hline CBCT & 1 & 1 & 1 & 7 & 5 & 4 & 13 & 1 & 1 & 2 & 7 & 5 & 2 & 12 & & & & & & \\
\hline \#48 & 0 & 2 & 1 & 11 & 12 & 7 & 57 & 0 & 2 & 1 & 11 & 12 & 11 & 53 & & & & & & \\
\hline Extracted & 0 & 1 & 0 & 4 & 4 & 1 & 20 & 0 & 1 & 0 & 4 & 3 & 3 & 19 & & & & & & \\
\hline Panoramic & 0 & 1 & 0 & 4 & 4 & 2 & 20 & 0 & 1 & 0 & 4 & 4 & 2 & 20 & & & & & & \\
\hline CBCT & 0 & 0 & 1 & 3 & 4 & 4 & 17 & 0 & 0 & 1 & 3 & 5 & 6 & 14 & & & & & & \\
\hline Total & 1 & 14 & 31 & 54 & 67 & 59 & 246 & 1 & 14 & 34 & 56 & 69 & 53 & 244 & 9 & 27 & 25 & 35 & 32 & 156 \\
\hline
\end{tabular}

\#18: maxillary right third molar; \#28: maxillary left third molar; \#38: mandibular left third molar; \#48: mandibular right third molar; CBCT: cone beam computed tomography; Developmental stages from 4 to 10 indicate initial root formation, $1 / 4$ of root formation, $1 / 2$ of root formation, $3 / 4$ of root formation, complete root formation, $1 / 2$ of apex formation and complete apex formation, respectively. 
Table 3 - Behavior of curves in the Receiver Operating Characteristic analysis based on the sensitivity in function of specificity for third molar staging extracted, in panoramic radiographs and in CBCT scans

\begin{tabular}{|c|c|c|c|c|c|c|c|c|c|}
\hline \multirow{3}{*}{$\begin{array}{l}\text { Specificity } \\
(\%)\end{array}$} & \multicolumn{9}{|c|}{ Sensitivity (\%) } \\
\hline & \multicolumn{3}{|c|}{ Extracted } & \multicolumn{3}{|c|}{ Panoramic radiograph } & \multicolumn{3}{|c|}{ CBCT scans } \\
\hline & Min. & Median & Max. & Min. & Median & Max. & Min. & Median & Max. \\
\hline 0 & 100 & 100 & 100 & 100 & 100 & 100 & 100 & 100 & 100 \\
\hline 10 & 81.66 & 100 & 100 & 70 & 90 & 100 & 100 & 100 & 100 \\
\hline 20 & 66.67 & 100 & 100 & 66.67 & 84 & 100 & 80 & 100 & 100 \\
\hline 30 & 50 & 83.33 & 100 & 54.44 & 83.33 & 100 & 56.67 & 97.41 & 100 \\
\hline 40 & 35.93 & 77.78 & 100 & 34 & 78.78 & 94.44 & 34.42 & 81.11 & 100 \\
\hline 50 & 29.99 & 71.27 & 94.44 & 19.44 & 66.67 & 94.44 & 22.22 & 61.11 & 100 \\
\hline 60 & 17.22 & 50 & 89.21 & 7.99 & 51.11 & 88.89 & 11.11 & 41.48 & 89.44 \\
\hline 70 & 0 & 38.06 & 78.9 & 5.33 & 27.78 & 77.06 & 0 & 27.78 & 67.78 \\
\hline 80 & 0 & 16.67 & 58.89 & 0 & 16.67 & 55.56 & 0 & 16.67 & 50 \\
\hline 90 & 0 & 3.33 & 38.89 & 0 & 7.41 & 33.33 & 0 & 0 & 33.33 \\
\hline 100 & 0 & 0 & 11.11 & 0 & 0 & 22.22 & 0 & 0 & 11.11 \\
\hline
\end{tabular}

Min.: lower bound; Max.: upper bound. 
Table 4 - Behavior of curves in the Receiver Operating Characteristic analysis based on the specificity in function of sensitivity for third molar staging extracted, in panoramic radiographs and in CBCT scans

\begin{tabular}{|c|c|c|c|c|c|c|c|c|c|}
\hline \multirow{3}{*}{$\begin{array}{c}\text { Sensitivity } \\
(\%)\end{array}$} & \multicolumn{9}{|c|}{ Specificity (\%) } \\
\hline & \multicolumn{3}{|c|}{ Extracted } & \multicolumn{3}{|c|}{ Panoramic radiograph } & \multicolumn{3}{|c|}{ CBCT scans } \\
\hline & Min. & Median & Max. & Min. & Median & Max. & Min. & Median & Max. \\
\hline 0 & 100 & 100 & 100 & 100 & 100 & 100 & 100 & 100 & 100 \\
\hline 10 & 61.11 & 83.33 & 100 & 59.33 & 88.89 & 100 & 61.11 & 83.33 & 100 \\
\hline 20 & 55.56 & 80 & 96.47 & 47.99 & 75.91 & 100 & 49.77 & 77.78 & 94.44 \\
\hline 30 & 44.44 & 75.56 & 94.44 & 43.31 & 67.07 & 100 & 42.21 & 67.78 & 94.44 \\
\hline 40 & 33.33 & 67.78 & 91.68 & 38.73 & 63.14 & 84 & 35.65 & 60.88 & 87.78 \\
\hline 50 & 33.33 & 61.11 & 87.53 & 33.33 & 61.11 & 83.33 & 31.48 & 55.56 & 81.48 \\
\hline 60 & 27.78 & 50.46 & 81.38 & 26 & 54.44 & 77.79 & 26.44 & 50.56 & 73.33 \\
\hline 70 & 16.67 & 50 & 72.22 & 10 & 46.9 & 73.78 & 22.22 & 45.56 & 69.03 \\
\hline 80 & 5.56 & 38.89 & 70.05 & 3.33 & 35.11 & 66.67 & 17.78 & 40.22 & 64.44 \\
\hline 90 & 5.56 & 22.22 & 57.78 & 0 & 10 & 55.01 & 14.44 & 35 & 58.89 \\
\hline 100 & 5.56 & 22.22 & 44.44 & 0 & 0 & 38.89 & 11.11 & 27.78 & 50 \\
\hline
\end{tabular}

Min.: lower bound; Max.: upper bound. 